Dobrowolsky: Empfindlichkeit des Anges gegen die Lichtintensität etc. 441

\title{
Ueber die Empfindlichkeit des Auges gegen die Licht- intensität der Farben (Farbensinn) im Centrum und auf der Peripherie der Netzhaut.
}

Von

Dr. W. Dobrowolsky.

1.

Ueber die Empfindlichkeit im Centrum der Netzhant. Kritik der verschiedenen Untersuchungsmethoden.

Wir besitzen gegenwärtig eine beträchtliche Anzahl von Thatsachen und Beobachtungen, die unzweifelhaft dafür sprechen, dass die Empfindliehkeit des Auges gegen blaue Farbe bei Weitem die gegen andere, weniger brechbare Spectralfarben übertrifft. Hierher gehören die allgemein bekannten Beobachtungen von Purkinje und Dove, die beweisen, dass unser Ange die blaue Farbe bei schwächerem Licht, die rothe dagegen bei stärkerem Licht wahrnimmt; dass die letztere bei einem Beleuchtungsgrade, bei der die erstere noch deutlich wahrgenommen wird, schwindet. Hierauf bezieht sich auch die zuerst von $\mathrm{Purkinje} \mathrm{bemerkte} \mathrm{und} \mathrm{darauf} \mathrm{auch}$ von andern Beobachtern bestätigte Thatsache, dass die blaue Farbe dem Auge fast bis zur äussersten Peripherie der Netzhaut blau erscheint, während alle übrigen Farben an der Peripherie der Netzhaut ganz andere Empfindungen hervorrufen, als im Centrum derselben. Am augenfälligsten jedoch sprechen für die grösste Empfindlichkeit der Augen gegen blaue Farbe die bemerkenswerthen Untersuchungen L e b e r's ${ }^{1}$ ), auf welche die Physiologen bisher leider wenig Aufmerksamkeit verwandt haben. Die Untersuchungen Leber's zeigen, dass bei Atrophie des Sehnerven in Folge der verschiederartigsten Ursachen, zugleich mit Abnahme der Sehschärfe auch die Empfindlichkeit des Auges gegen Farben fällt, und zwar vor Allem gegen die rothe und grüne, während die gegen Blau am

1) Archiv für Opthhalmol. Bd. XV, III. S. 52. 
längsten erhalten bleibt, dass somit destructive Processe im Nerven selbst und im Gehirn (bei Atrophie centralen Ursprungs) verhältnissmässig schwerer und nicht so schnell auf die Empfindlichkeit des Auges gegen Blau ihren Einfluss äussern.

Aber trotz dieser überzeugenden Thatsachen und Beobachtungen haben directe Untersuchungen über die Empfindlichkeit des Auges gegen Farben, die von verschiedenen Beobachtern angestellt worden sind, $\mathrm{zu}$ verschiedenen und einander widersprechenden Resultaten geführt.

L a mansky ${ }^{1}$ ) hat bei der Untersuchung der Empfindlichkeit gegen Farben auf den Vorschlag von $\mathrm{Hel} \mathrm{m} \mathrm{holtz}$ eine Methode angewandt, gegen die sich im Princip nichts einwenden lässt. Das Wesentliche seiner Methode bestand darin, dass er die Farben des Spectralapparates isolirte und jedes Farbenfeld einzeln durch ein doppelbrechendes Prisma aus Kalkspath betrachtete. Die in Folge dessen entstandenen Farbenfelder besassen dadurch einen verschiedenen Grad von Intensität, dass $\mathrm{L}$ a $\mathrm{m}$ a n $\mathrm{s} \mathrm{k}$ y das Licht, das auf die Spalte des Spectroskops fiel, polarisirte, indem er dasselbe vorher durch ein Bündel planparalleler Glasplatten passiren liess. Indem er die Grösse des Winkels, den die einfallenden Lichtstrahlen mit der Normalen der Glasplatten bildeten, veränderte, konnte er willkürlich die Intensität eines Farbenfeldes soweit ändern, bis das Auge schon nicht mehr im Stande war, irgend welchen Untershhied in der Intensität beider Farbenfelder wahrzunehmen. Zu gleicher Zeit suchte $\mathrm{L}$ a $\mathrm{m}$ a $\mathrm{n} \mathrm{s} \mathrm{k}$ y das Maximum der Empfindlichkeit für jede Spectralfarbe zu finden, was sehr wichtig ist und später von einigen Beobachtern völlig ausser Acht gelassen wurde. Zu dem Behuf vergrösserte er die Intensität jeder zu untersuchenden Farbe so lange, bis die grösste Empfindlichkeit erzielt wurde und bis sie constant blieb.

Bei der Handhabung seiner Methode erlaubte sich jedoch $\mathrm{L}$ a $\mathrm{mansky}$ in einigen Specialitäten solche Vorkehrungen, die nothgedrungen ungünstig auf die Richtigkeit der von ihm erhaltenen Resultate einwirken mussten. So liess er die Sonnenstrahlen, bevor sie auf die Spalte des Spectroskops fielen, ein mattgeschliffenes Glas passiren, um eine gleichmässige Lichtquelle zu erhalten und darauf durch planparallele Platten hindurchgehen, um das Licht zu pola-

1) Archiv für Ophthalmol. Bd. XVII, I. S. 125. 
Ueber die Empfindlichkeit des Auges gegen die Lichtintensität etc. 443

risiren. Um aber die Intensität der Farben zu vergrössern, und dadurch die grösstmöglichste Empfindlichkeit für jede derselber zu erzielen, stellte er seine Untersuchungen bei verschiedener Breite der Spalte an, wobei er von $0,12 \mathrm{Mm}$. ausging und darauf jedes Mal die Breite zweimal vergrösserte, so dass diese bei der letzten Reihe seiner Versuche schon 1,2 Mm. betrug. In dieser Abschwächung des Sonnenlichts durch ein mattgeschliffenes Glas und in der Erweiterung der Spalte liegt eben die schwache Seite seiner Untersuchungen.

Es ist klar, dass sich die natürliche Stärke des direkten Sonnenlichts durch eine Erweiterung der Spalte des Spectralapparates in keiner Weise ersetzen lässt; die Möglichkeit eines solchen Ersatzes zugeben, hiesse die Qualität durch die Quantität ersetzen, hiesse die Möglichkeit der Ausführung solcher Untersuchungen im Dämmerlicht zugeben, wenn man nur die Spalte entsprechend erweitert. Da bei L a m a $\mathbf{n}$ sky die Erweiterung der Spalte für alle Spectralfarben eine gleiche war, so ist es klar, dass bei Erweiterung der Spalte die Helligkeit aller Farben gleichmässig vergrössert wurde und dass somit bei ihm die Helligkeit der blauen und violetten Farbe im Vergleich mit den übrigen Spectralfarben zu schwach war und nicht dazu hinreichen konnte, um das Maximum der Empindlichkeit zu erreichen. Selbstverständlich waren auch bei gleichmässiger Vergrösserung der Helligkeit sämmtlicher Spectralfarben das Gelb und Grün unvergleichlich intensiver als das Blau und Violett, wodurch auch der Umstand erklärt wird, dass bei La man sky die grösste Fmpfindlichkeit für Gelb und Grün ausfiel. Aber ausserdem führte die Erweiterung der Spalte noch den grossen Nachtheil herbei, dass man bei starker Breite derselben $=1,2 \mathrm{Mm}$. kein reines Spectrum erhalten, keine homogenen Spectralfarben haben konnte.

$\mathrm{L}$ a $\mathrm{m}$ a $\mathrm{n} \mathrm{s} \mathrm{k}$ hätte seinen Zweck richtiger erreicht, wenn er bei seinen Untersuchungen directes Sonnenlicht angewandt und bei constanter Breite der Spalte die Helligkeit für jede Spectralfarbe speciell dadurch verändert hätte, dass er bald das Sonnenlicht vermittelst einer Convexlinșe concentrirte und zwar für die minder hellen Spectralfarben, Blau und Violett, bald wiederum directes nicht concentrirtes, ja sogar leicht geschwächtes Sonnenlicht für die hellsten Spectralfarben, Gelb und Grün, anwandte und auf diese Weise fortfuhr, die Intensität so lange zu verändern, bis für jede Farbe die grösste Empfindlichkeit erzielt wurde. Uebrigens wäre 
möglich, dass L a m a n s $\mathrm{k}$ y in Folge von Eigenthümlichkeit seiner Augen directes Sonnenlicht vermeiden musste, wenn diese hinreichend helles Licht nicht vertragen konnten.

Was andere Beobachter, welche sich mit der vorliegenden Frage beschäftigt haben, anbetrifft, so finden wir bei einigen von denselben Missverständnisse, die daraus hervorgehen, dass sie, dem Anschein nach, die wesentlichsten und elementarsten Begriffe: Fa rbenton und Intensität des farbigen Lichts mit einander verwechselt e $n$. So vergleichen $R$ a e hl man $n^{1}$ ) und $S c h o ̈ n^{2}$ ) die Resultate verschiedener Beobachter über die Empfindlichkeit des Auges gegen Farben, stellen die von mir und Lamansky erhaltenen Resultate mit denen von $\mathrm{Mandelstamm}$ über denselben Gegenstand zusammen und finden zwischen beiden einen Widerspruch. Schön folgert sogar auf Gruud dieses Widerspruchs in den Resultaten, dass Letztere unbrauchbar sind. (!) Dabei haben die

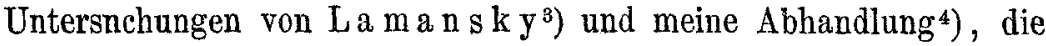
sie anführen, die Empfindlichkeit des Auges gegen In te n sität der Spectralfarben zum Gegenstande, während die Arbeit von M a ndelsta $\mathrm{m} \mathrm{m}^{5}$ ) auf welche sie sich berufen, die Empfindlichkeit des Auges gegen F arbentöne hehandelt. Aus diesem Grunde ist es undenkbar, die Resultate von Mandelstamm mit den von mir und L a m a $\mathrm{n}$ s $\mathrm{y}$ erhaltenen Resultaten vergleichen $\mathrm{zu}$ wollen.

R a e $1 \mathrm{mann}^{6}$ ) hatte sich als Aufgabe gestellt, das Minimum des farbigen Lichts zu bestimmen, welches das Ange im Stande ist wahrzunehmen. $\mathrm{Zu}$ dem Zwecke entfernte er aus dem Spectroskope das Ocular und ersetzte es durch ein Rohr, in welchem sich zwei Nicol'sche Prismen befanden. Bekanntlich besitzt das Licht, welches zwei Nicol's passirt, das Maximum von Helligkeit dann, wenn die Hauptschnitte derselben einander parallel sind; wenn dagegen die Hauptschnitte mit einander einen Winkel von $90^{\circ}$ bilden, so lassen die Prismen schon keine Lichtstrahlen mehr hindurch. Diese letztere Stellung des Nicol's nahm Ra ehlmann als die Ausgangsstellung an und drehte hierauf den zweiten, näher zum
1) Graefe's Archiv, Bd. XX, I. S. 243.
2) Graefe's Archiv, Bd. XX, II. S. 276.
3) Archiv für Ophthalnol. Bd. XVII, I. S. 125-130.
4) Archiv für Ophthalmol. Bd. XVIII, I. S. 75-92.
5) Archiv für Ophthalmol. Bd. YVIII, II. S. 399-406.
6) Archiv für Ophthalmol. Bd. XX, I. S. 233-236. 
Ueber die Empfindlichkeit des Auges gegen die Lichtintensität etc. 445

Auge befindlichen Nicol so lange, bis eine Farbenempfindung auftrat. Die Grösse dieses Drehungswinkels war für verschiedene Spectralfarben eine verschiedene und aus dieser Grösse berechnete Raehlmann die Empfindlichkeit des Auges gegen verschiedene Farben. Wi e man a priorierwartenkonnte, ergab sich die geringste Grösse des Drehungswinkels des zweiten Nicol und folglich die grösste Empfindlichkeit für grüne Farbe.

Bei Anwendung der beschriebenen Methode konnte Ra ehlmann aus zwei Gründen zu befriedigenden Resultaten nicht gelangen: 1) alle unsere Licht- und Farbenempfindungen charakterisiren sich bei einem Minimum von Helligkeit durch ausserordentliche Unzuverlässigkeit und Unbeständigkeit, wie dieses schon $\mathrm{Fechn}$ er dargethan hat. Und dies ist vollkommen verständlich, da auf solche Empfindungen häufig schwer zu entdeckende und verhältnissmässig unbedeutende Umstände einen beträchtlichen Einfluss ausüben, wie z. B. der Zustand des Auges selbst, seine grössere oder geringere Ermüdung, Eindrücke von anderen Gegenständen; daher sind bei Empfindungen, die nahe an der unteren Grenze der Empfindlichkeit stehen, grosse Schwankungen gewöhnlich unvermeidlich. Daher ist es am vortheihaftesten, die uns beschäftigenden Untersuchungen über Empfindlichkeit des Auges bei einem Maximum von Helligkeit an ihrer oberen Grenze, die dem.Maximum der Empfindung entspricht, anzustellen. Hier besitzt die Empfindung einen beständigeren Character und ist nicht so starken Schwankungen unterworfen, wie an der unteren Grenze. 2) Die Methode von $R$ a e $1 \mathrm{~m}$ a $\mathrm{n}$ n liesse sich allenfalls in dem Falle anwenden, wenn alle Spectralfarben eine gleiche Helligkeit besässen oder wenn wir sie wenigstens künstlich zu demselbẹn Grade von Helligkeit bringen könnten. Da wir aber nicht im Stande sind, dieses zu thun, so hat $\mathrm{R}$ a e $\mathrm{hlm}$ a $\mathrm{n}$ n bei Bestimmung des Minimums für verschiedene Farben de facto verschiedenartige Grössen mit einander verglichen, die in keiner Weise mit einander zu vergleichen sind.

Wenn er die grüne Farbe bei einem kleineren Drehungswinkel wahrnehmen konnte, als alle übrigen Farben, so geschah dieses durchaus nicht dadurch, dass sein Auge empfindlicher gegen Grün war, sondern nur dadurch, dass die grüne Spectralfarbe im Vergleich mit der rothen und blauen eine unvergleichlich grössere Helligkeit besitzt und in Folge dessen trotz des kleineren Drehungswinkels eine bedeutend grössere Menge grüner Strahlen zu seiner Netzhaut ge- 
langten im Vergleich mit der Menge z. B. blauer Strahlen bei demselben Drehungswinkel.

Dasselbe Resultat können wir viel einfacher und schneller erreichen, wenn wir das Spectroskop allein anwenden. Wenn wir die gegen Licht gerichtete Collimoturspalte nach und nach öffnen, so unterscheidet das Auge zuerst gewöhnlich die grüne Farbe, natürlich desshalb, weil deren Helligkeit im Vergleich mit den übrigen F'arben sehr gross ist. Dieser Versuch ist mit dem von $R$ a ehlmann völlig identisch.

$\mathrm{Zu}$ den oben angeführten Nachtheilen der Raehlma nn'schen Methode muss noch hinzugefügt werden, dass er bei seinen Untersuchungen nicht directes Sonnenlicht anwandte, sondern Licht, welches von einem weissen, durch Sonnenlicht beleuchteten Papier auf einen Spiegel reflectirt wurde. In der Folge wandte er, um eine beständige Lichtquelle zu besitzen, eine Petroleumlampe an.

Zum Schluss unserer Bemerkungen über die Arbeit $\mathrm{R}$ a e h $\mathbf{l}$ mann's müssen wir noch anführen, dass er bei seinen Berechnungen einen grossen Fehler begangen hat. Er nimmt nämlich an, dass bei Drehung des zweiten Nicol bei verschiedenen Winkeln, die die Hauptabschnitte der beiden Nicols bilden, d ie erhalten en Intensitätensich zu einander verhalten, wiedie Quadrate der Sinus dieser Winkel, während diese Intensitäten in der That zu einander im Verhälnisse der Quadrateder Cosinus stehen. Der hieraus hervorgehende Fehler ist zu gross, als dass er ignorirt werden dürfte.

Die von $B \circ \mathrm{hn}^{x}$ ) angewandte Methode ist im Princip unantastbar, zeigt aber in der Beziehung eine Unbequemlichkeit, dass bei ihr in Folge von Reflexion des Lichts ein Spectrum von geringer Helligkeit erhalten wird, so dass man mit ihr das Maximum der Empfindlichkeit gegen Farben und namentlich gegen diejenigen, die sich an den Räudern des Spectrums befinden, nicht erreichen kann. Da das Auge von $\mathrm{Boh} \mathbf{n}$ seiner Angabe nach geringe Unterschiede in der Intensität nur in dem Falle wahrnehmen konnte, wenn die zu vergleichenden Felder sehr schwach erleuchtet waren, wenn somit die Untersuchungen nahe bei der unteren Grenze der Empfindungen angestellt wurden; so erklären sich hierdurch vollkommen jene unbestimmten und widersprechenden Resultate, die Bohn erlangte,

1) Poggendorf's Annal. Ergänzungs-Band VI. S. 384-403. 
Ueber die Empfindlichkeit des Auges gegen die Lichtintensität etc. 447

d. h. dass die Empfindlichkeit seiner Augen an verschiedenen Tagen eine verschiedene war, dass an verschiedenen Tagen eine verschiedene Helligkeit der Farben zur Erreichung der grösstmöglichen Empfindlichkeit erforderlich war u. s. w.

Ausserdem klagt $\mathrm{Bohn}$ bei seinen Versuchen über Blendung und in Folge dessen über grosse Abnahme der Empfindlichkeit; da nun aber bei ihm diese Blendung sogar bei sehr geringer Helligkeit und zwar bei einer bedeutend schwächeren erfolgte, als die, welche wir beim Lesen und Schreiben für bequem halten, so folgt hieraus nothwendigerweise der Schluss, dass die Augen von $\mathrm{Bobn}$ an Photophobie leiden und nicht den Grad von Energie besitzen, welcher unbedingt für solche Untersuchungen nothwendig ist.

Endlich müssen wir noch einer Arbeit von $\mathrm{K} \mathrm{unk}$ el ${ }^{1}$ ) erwähnen, die eine indirekte Beziehung zu dem uns beschäftigenden Gegenstande besitzt. $\mathrm{K} \mathrm{u} \mathrm{nkel}$ bestimmte die Abhängigkeit der Farbenempfindungen von der Zeit und fand, dass verschiedene Theile des Spectrums eine verschiedene Zeit erfordern, um das Maximum der Reizung hervorzubringen und dass diese Zeit für Roth die kürzeste ist und darnach für Blau und Grün. Kunkel war sich hierbei dessen wohl bewusst, dass die von ihm erhaltenen Zahlen mit einander nicht verglichen werden konnten, weil sie bei Untersuchung von Spectralfarben gewonnen waren, die einen verschiedenen Grad von Helligkeit besassen und weil eine grössere Helligkeit der Farbe in einer kürzeren Zeit das Maximum der Reizang bewirkt. Um aus dieser Verlegenheit zu kommen, nahm $\mathrm{Kunkel}$ willkürlich an, dass im Spectrum einer Petroleumlampe die Intensität der grünen Farbe zweimal grösser, als die der rothen und viermal grösser, als die der blauen sei und führte nun auf Grund dieser in keiner Weise bewiesenen Annahme in den erhaltenen Zahlen Verbesserungen ein. Wir können es durchaus nicht für zulässig halten, dass man in wissenschaftlichen Untersuchungen seine Zuflucht zu solchen kühnen und willkürlichen Griffen nähme, um so mehr, als Kunckel trotz dessen keinen Anstand nahm, die Resultate seiner Untersuchungen mit den Resultaten von Lamansky zu vergleichen, während doch dieser letztere sich etwas derartiges nicht hatte zu Schulden kommen Iassen.

In der angeführten Beschreibung der verschiedenen Methoden

1) Archiv für die gesammte Physiol. von Pflüger. Bd. I, IX, H. IV und V. S, 206-207, 
fällt uns am meisten der Umstand auf, dass die verschiedene Intensität der Spectralfarben hauptsächlich die Beobachter irreführte und sie daran hinderte, zu Resultaten zu gelangen, die mit den Beobachtungen von Dove, Purkinje und Leber, auf die wir oben hingewiesen haben, harmonirt hätten. Einige Beobachter (Raehlmann, Bohn) ignorirten gleichsam bei ihren Untersuchungen die Thatsache, dass die Spectralfarben eine verschiedene Helligkeit besitzen; andere dagegen (L amanskyKunkel) sahen zwar bei ihren Untersuchungen ein, dass man diese Thatsache berücksichtigen müsse, aber sie konnten die sich ihnen entgegenstellende Schwierigkeit nicht umgehen und auf den richtigen Weg gelangen. Da sich die grösste Intensität des Spectrums in dessen Mitte, zwischen den Linien $\mathrm{D}$ und $\mathrm{E}$, befindet und darauf nach beiden Seiten zu abnimmt, so folgte hieraus eben der Umstand, dass die grösste Empindlichkeit bei der Mehrzahl der Beobachter (Lamansky, Raehlmann, Bohn) auf den Antheil der grünen Farbe kam.

Hieraus folgt nun von selbst die Nothwendigkeit, dass man bei den in Rede stehenden Untersuchungen sich an bestimmte, nach Möglichkeit auf wissenschaftliche Thatsachen begründete Regeln $\mathrm{zu}$ halten habe. Da wir einerseits keine Mittel besitzen, allen Spectralfarben einen gleichen Grad von Helligkeit zu verleihen und nicht einmal sicher darüber urtheilen können, ob zwei verschiedene Farben den gleichen Grad von Intensität besitzen, es aber andererseits möglich ist, dass die grösste Empfindlichkeit gegen verschiedene Farben bei verschiedenen Helligkeitsgraden ausfällt, so bleibt uns bei den uns beschäftigenden Untersuchungen nichts Anderes übrig, als einzeln für jede Farbe das Maximum der Empfindlichkeit zu ermitteln. Hierbei ist es am geeignetsten mit schwachen Helligkeitsgraden zu beginnen, die man dann nach und nach solange zu vergrössern hat, bis die Empfindlichkeit am grössten erscheint und innerhalb bestimmter Grenzen constant bleibt, über welche hinaus sie in Folge von Blendung wieder zu sinken beginnt.

Es bedarf wohl kaum des Beweises, dass zu diesem Zweck das Sonnenlicht bedeutend mehr Vortheile darbietet, als alle anderen Lichtquellen. Zudem verfügen wir ja über eine grosse Menge von Mitteln, um willkürlich die Intensität des Sonnenspectrums zu schwächen oder zu verstärken. Wenn wir die Helligkeit desselben vergrössern wollen, können wir directes Sonnenlicht benutzen, das- 
Ueber die Empfindlichkeit des Auges gegen die Lichtintensität etc. 449

selbe sogar concentriren, indem wir zu dem Behuf starke Convexlinsen anwenden und die Spalte in den Brennpunkt der Linse stellen, so dass wir in der Spalte ein Sonnenbild erhalten. Um die Intensität des Spectrums zu schwächen, wie dies bei der Untersuchung der hellsten Farben, des Gelb und Grün, erforderlich sein kann, können wir einfache Glasplatten, mattgeschliffenes Glas, Nicol'sche Prismen, am besten und einfachsten jedoch Convexlinsen benutzen, indem wir hierbei die Spalte des Spectralapparats ausserhalb des Brennpunktes der Convexlinse stellen; wenn wir nun willkürlich den Abstand zwischen dem Brennpunkt der Linse und der Spalte vergrössern, können wir auf der letzteren einen Zerstreuungskreis von beliebiger Grösse erhalten und dadurch die Intensität des Spectrums in erwünschtem Grade abschwächen.

Als ich mich im Sommer des Jahres 1874 mit der Untersuchung der Empfindlichkeit gegen Farben auf der Peripherie der Netzhaut beschäftigte, prüfte ich aufs Neue meine im Laboratorium von Helmholt $z^{1}$ ) gemachten Untersuchungen hinsichtlich der centralen Empfindlichkeit, indem ich dabei alle jene nothwendigen Bedingungen und Regeln beobachtete, von denen oben bei Besprechung der verschiedenen Methoden die Rede war. Ich beschränkte mich hierbei nur auf drei Farben - Roth in der Linie B, Grün zwischen D und $\mathrm{E}$, Indigo zwischen F und G. Die dabei erhaltenen Resultate stimmen fast vollkommen mit den von mir im Laboratorium von Helmholtz früher gewonnenen überein: die Empfindlichkeit gegen Roth $=\frac{1}{19,7}$, gegen Grün $=\frac{1}{58,7}$, gegen Blau $=\frac{1}{268}$. Nur die Empfindlichkeit gegen Blau ergab sich jetzt bisweilen als eine etwas grössere, was durch die günstigeren Verhältnisse, unter denen ich hier in Petersburg meine Beobachtungen anstellte, erklärlich ist, da ich letztere im Sommer bei völlig hellem und wolkenlosem Himmel ausführte, während in Berlin die Beobachtungen im Winter stattfanden. Die von mir gewonnenen Resultate stehen in vollem Einklange mit den oben angeführten Beobachtungen von Dove, $\mathrm{Pur}$ kinje und Leber und erklären sogar diese. Ausserdem wurden diese Resultate durch zwei andere Beobachter im Laboratorium von Helmholtz, durch die Herren Berthold aus Königsberg und Pedro Garza aus Mexico bestätigt.

1) Archiv für Ophthalmolog. Bd. XVIII, I. S. 75-92, 
Dabei muss ich einen besonderen Nachdruck darauf legen, dass ich, um die grösste Empfindlichkeit gegen blaues Licht zu erhalten, directes Sonnenlicht anwenden musste, indem ich dasselbe vermittelst einer starken Convexlinse auf der Spalte des Spectralapparats, die im Brennpunkt der Linse stand, concentrirte. Dabei erhielt man ein Spectrum von blendender Helligkeit, welches die gesundesten Augen nicht lange ohne Ermüdung ertragen können, so dass man die Untersuchung häufig unterbrechen musste, um den Augen eine Erholung zu gestatten. Einige, denen ich ein solches Spectfum zeigte, waren entschieden nicht im Stande, seine Helligkeit zu ertragen, obgleich ihre Augen keinerlei krankhafte Veränderungen zeigten.

Hieraus folgt nun von selbst, dass fïr dergleichen Untersuchungen Augen nothwendig sind, welche die stärkste Helligkeit des Spectrums ertragen können, und dass hingegen schwache, lichtscheue Augen das Maximum der Empfindlichkeit nicht erreichen können, welches man bei derlei Untersuchungen zu erstreben hat. Es wäre somit wünschenswerth, dass diejenigen Beobachter, deren Augen kein starkes Licht ertragen, ihre Resultate wenigstens durch die Augen Anderer prüfen liessen.

II.

Ueber die Empfindlichkeit gegen Spectralfarben anf der Peripherie der Netzhaut,

Wenn schon in Bezug auf die Empfindlichkeit gegen Farben im centralen Theile der Netzhaut eine solche Meinungsverschiedenheit herrscht, so finden wir in Bezug auf die Empfindlichkeit auf der Peripherie derselben theils grosse Lücken, theils Widersprüche auf jedem Schritt. Bis jetzt giebt es noch keine Untersuchungen darüber, wie weit vom Centrum ab und mit welcher Schnelligkeit die Empfindlichkeit gegen Farben zu fallen beginnt. Der Versuch Ra ehl man $\mathrm{s}$ in dieser Beziehung gabihm in Folge der Unvollkommenheit seiner Methode, von welcher oben die Rede gewesen ist, keinerlei Resultate. Selbst die Grenzen des Gesichtsfeldes sind für die einzelnen Farben noch nicht genau bestimmt: nach Helmholt $z$ und Schelske ist die äusserste Peripherie der Netzhaut gegen Roth unempfindlich; nach Woinow bleiben an der 
äussersten Peripherie nur Licht percipirende Elemente übrig, während keine Elemente vorhanden sind, welche Farben percipiren; Sc hir m er dagegen behauptet, dass an der äussersten Peripherie nur die Perception der blauen Farbe erhalten bleibt; Landolt endlich will versichern, dass alle Farben bis an die äusserste Peripherie hin percipirt werden, wenn sie nur hinreichend intensiv sind. Die Beobachter können unter einander nicht einmal in der Entscheidung dieser so einfachen Frage übereinstimmen, ob nämlich die Grösse des farbigen Objects einen Einfluss auf die Grösse des Gesichtsfeldes ausübt.

Ein solcher Widerspruch kann vielleicht in einer geringen Anzahl von Fällen durch individuelle Eigenthümlichkeiten der Augen erklärt werden; in der Mehrzahl der Fälle jedoch hing die Entscheidung der Frage davon ab, welches farbige Papier die Beobachter benutzten; wenn grünes Papier intensiver war, als andere Farbenpigmente, so wurden auch die Grenzen des grünen Feldes als die grössten erhalten. Daher machte ich mich auch an die Untersuchung der Empfindlichkeit auf der Peripherie der Netzhaut gegen Spectralfarben mit der Absicht, zu bestimmen, ob die Empfindlichkeit allmählig abnimmt, in welchem Maase und wie weit sie an der Peripherie erhalten bleibt. $\mathrm{Zu}$ meinen Untersuchungen wählte ich drei Farben: roth, g r ün und indigo.

Die Methode ${ }^{1}$, deren ich mich bediente, war dieselbe, welche ich im Laboratorium von Helmholtz zur Bestimmung der Empfindlichkeit im Centrum der Netzhaut anwandte. Vor dem Spectroskop befanden sich zwei Nicols, deren Hauptschnitte einander parallel waren, und zwischen den Nicols eine Gypsplatte von circa $7 \mathrm{Mm}$. Dicke, welche sich um die optische Axe der Nicols drehte, so dass die vermittelst Heliostats gerichteten Lichtstrahlen Anfangs die beiden Nicols und die Gypsplatte passirten und darauf durch das Prisma in Farben zerlegt wurden. Bei Drehung der Gypsplatte um die Axe der Nicols finden sich 4 Stellen, wo in Folge von Interferenz der Lichtstrahlen eine Menge dunkler, den Fraunhofer'schen paralleler Linien auftritt, und 4 Stellen, wo diese Streifen in Folge von Aufhören der Interferenz völlig schwinden. Der Beobachter dreht die Gypsplatte und bemerkt, wann die dunklen Streifen im Spectrum an einem der vier Stellen auftreten und ver-

1) Archiv für Ophthalmolog. Bd. XVIII. I, 
schwinden und bezeichnet die Anzahl von Graden, um welche man die Platte vom Moment des Verschwindens der Streifen bis zu ihrem abermaligen Auftreten drehen musste; auf die Weise erhält man die Grösse des Winkels $2 \alpha$, nach der man den Unterschied zwischen der Intensität der dunklen und hellen Streifen berechnet. Der Sinn der ganzen Vorrichtung besteht darin, dass jeder helle Streifen ein Gesichtsfeld repräsentirt, in welchem die Intensität $=1$ ist und bei Drehung des Nicols unverändert bleibt; der dunkle Streifen dagegen stellt ein Gesichtsfeld dar, in welchem die Helligkeit bei Drehung der Platte von 0 bis $45^{\circ}$ nach und nach von 0 bis 1 zunimmt. Wenn nun der Beobachter mit seinem Auge beachtet, wann die dunklen Streifen zu schwinden und wieder aufzutreten beginnen, nimmt er zugleich wahr, wann die Helligkeit der beiden Felder oder Streifen eine fast gleiche wird. Wenn er nun den Unterschied zwischen der Helligkeit beider Streifen bestimmt, so bestimmt er zugleich auch den geringsten Unterschied in der Helligkeit beider Felder, welchen sein Auge an verschiedenen Stellen des Spectrums wahrzunehmen im Stande ist. Dieser geringste Unterschied ist $=\sin ^{2} 2 \alpha$.

Behufs Untersuchung der peripherischen Theile der Netzhaut war das Spectroskop so auf einen Halbkreis gestellt, dass das Fernrohr des Spectroskops den Halbkreis in zwei gleiche Theile theilte. Das beobachtende Auge befand sich im Centrum des Halbkreises und zu gleicher Zeit gegenüber der Mitte der Oeffnung des Oculars in einer Enfernung von 3 Cc. von demselben; hierbei stützte sich der Kopf auf eine zu diesem Zweck gemachte Unterlage, um dasselbe in einer bestimmten Lage zu erhalten. Beim Beginn der Untersuchung. wurde das Auge vor dem Spectroskop stets auf die Weise in einer Lage fixirt, dass seine Sehlinie durch das Centrum des Oculars ging und darauf wurde das Auge anf die eine oder die andere Seite vom Spectroskop auf die erwünschte Zahl von Graden abgelenkt, indem zu dem Zwecke der Gegenstand, der sich längs einem Bogen desHalbkreises bewegte, fixirt wurde. Somit beobachtete das Auge bei Drehung der Gypsplatte das Spectrum mit der Peripherie seiner Netzhaut und bemerkte, wann die dunklen Streifen schwanden und wiederum im Spectrum auftraten.

Um die zu untersuchende Farbe $z u$ isoliren, war in das Ocular des Fernrohres ein Schirm mit einer Quadratoffinung in der Mitte eingestellt. Die Oeffnung besass eine hinlängliche Breite, so dass 
in derselben die rothe Farbe auf der Ausdehnung von der Linie a bis C Raum fand. Die grüne Farbe wurde in der Nähe der Linie E untersucht und durch die genannte Oeffnung war der grösste Theil des grünen Spectrums sichtbar. Bei der Untersuchung der blauen Farbe lag in dem Gesichtsfelde der näher zur Linie G liegende Theil des Spectrums.

Die Untersuchungen wurden in der Hinsicht unter den günstigsten Bedingungen angestellt, als im Laufe des Sommers 1874 fast beständig klare und wolkenlose Tage waren und das Spectrum somit eine grosse Helligkeit besass. Bei Untersuchung jedoch der rothen und besonders der blauen Farbe concentrirte ich das Sonnenlicht vermittelst einer Convexlinse No. 2, indem ich die Spalte in deren Brennpunkt stellte, wodurch die Empfindlichkeit gegen diese Farben bedeutend zunahm. Ohne diese Concentration wäre die Helligkeit der rothen und besonders der blauen Farbe zu schwach gewesen und dann wäre die Empfindlichkeit gegen diese Farben weit von ihrem Maximum zurückgeblieben. Bei Untersuchung der peripherischen Theile der Netzhaut muss man um so mehr sein Augenmerk auf eine genügende Helligkeit der zu untersuchenden Farben richten, als die Bilder der leuchtenden Gegenstände selbst im Maasse der Annäherung zur äussersten Peripherie immer mehr und mehr ihre Intensität verlieren.

Allein wir müssen zugestehen, dass diese Untersuchungen mit bedeutenden Schwierigkeiten verbunden sind: 1) Eine genaue Fixation des Objects ist bei der äussersten Adduction und Abduction des Auges sehr schwierig und kann wegen schneller Ermüdung der Muskel nicht lange anhalten. Daher ist es bei allen seitlichen $\mathrm{Ab}$ lenkungen des Anges über $30^{\circ}$ vortheilhafter die Bewegungen der Augen durch Wendungen des Kopfes auf die entsprechende Seite zu ersetzen; 2) ein zweiter Umstand, der die Untersuchung erschwert, besteht darin, dass die Peripherie der Netzhaut ungemein schnell ermüdet und ihre Empfindlichkeit dabei abnimmt. Auf diese Ermüdung machte zuerst $A$ u be $\mathrm{r}$ t aufmerksam, leider haben sie aber spätere Beobachter nicht gebührend beachtet. Bei den Untersuchungen kann man sich täglich davon überzeugen, dass die dunklen Streifen im Spectrum, welche zu Anfang der Untersuchung von der Peripherie der Netzhaut deutlich wahrgenommen werden, bald vollkommen verschwinden und wieder auftreten, wenn man das Auge auf einige Sekunden schliesst; je näher zur äussersten Peri- 
pherie der zu untersuchende Theil der Netzhaut liegt, desto schneller ermüdet er und desto eher verschwindet sogar völlig jede Farbenempfindung. Die schnelle Ermüdung der Netzhautperipherie verdient um so mehr Beachtung, als sie schon oftmals Veranlassung zu falschen Schlüssen und unrichtigen Erklärungen gab. So fand Ra ehlmann ${ }^{1}$ ) dass die Peripherie der Netzhaut gegen Violett empfindlicher sei, als ihr Centrum; etwas Aehnliches fanden auch andere Beobachter. In Wirklichkeit verhält sich die Sache aber ganz anders. Das Centrum der Netzhaut ermüdet ebenfalls durch Farben, obgleich nicht so schnell, wie ihre Peripherie, in Folge dieser Ermüdung kann die Empfindlichkeit des Centrums um zwei Mal und sogar bedeutend mehr abnehmen; wenn nun aber das zu untersuchende Farbenfeld sehr geringe Dimensionen besitzt, so kann die Farbenempindung sogar völlig schwinden. Wenn das Auge hierbei eine geringe Bewegung zur Seite macht, so wird die Farbenempfindung in Folge dessen deutlicher, dass das Bild des farbigen Ojectes auf einen weniger ermüdeten Theil der Netzhaut fällt, welcher in Folge dessen verhältnissmässig empfindlicher wird. $\mathrm{Zu}$ Anfang meiner Untersuchungen war ich gleichfalls geneigt, in einigen Fällen der Peripherie der Netzhaut eine grössere Empfindlichkeit zuzuschreiben, allein die oben angeführte Beobachtung $\mathrm{A} \mathrm{u} b$ e r t's befreite mich alsbald von diesem Irrthum, als ich meine Untersuchungen häufiger zu unterbrechen begann, um dem Auge die nöthige Erholung zu gewähren, so dass jede einzelne Messung für eine bestimmte Stelle der Netzhaut und für eine Farbe nur eine kurze Zeit und dabei mit Unterbrechungen stattfand.

Ich führe die Resultate meiner Untersuchungen in den unten beigefügten Tabellen an, von denen die Tabelle $\mathrm{A}$ die allmählige $\mathrm{Ab}$ nahme der Empfindlichkeit gegen Farben an der inneren Hälfte der Netzhaut oder am äusseren Theile des Gesichtsfeldes, die Tabelle B dagegen an der äusseren Hälfte der Netzhaut oder an dem inneren Theil des Gesichtsfeldes darstellt. In der ersten Colonne einer jeden Tabelle ist die Anzahl von Graden bezeichnet, um welche die Sehlinie des zu untersuchenden Auges seitlich abgelenkt war und neben jeder Zahl von Graden stehen drei Colonnen für drei Farben und in einer jeden Colonne stehen somit der Reihe nach drei Grössen : 1) die

1) 1. c. S. 250 . 
Ueber die Empfindlichkeit des Auges gegen die Lichtintensität etc. 455

Grösse des Winkels $2 \alpha$;2) die aus diesem berechnete Empfindlichkeit gegen die betreffende Farbe und 3) das Verhältniss der für diese Stelle der Netzhaut ermittelten Empfindlichkeit zur centralen Empfindlichkeit, um anschaulich darzustellen, um welche Grössen die Empfindlichkeit in der Richtung vom Centrum zur Peripherie abnimmt; somit zeigen die angeführten Verhältnisse $1: 3$ oder $1: 5$ an, dass an der betreffenden Stelle der Peripherie die Empfindlichkeit um 3 oder 5 mal schwächer ist, als die centrale. Für den Winkel $\alpha$ ist die Mittelzahl von 15-25 Abzählungen genommen; hierbei sind vornehmlich runde Zahlen gewählt, da bei grösseren Winkeln, über $20^{\circ}$, ein Unterschied von einigen Minuten, und bei noch grösseren Winkeln sogar ein Unterschied von einem halben Grad bei der Berechnung der Empfindlichkeit nur eine höchst geringe Differenz ergiebt. Die bei den einzelnen Abzählungen gewonnenen Zahlen zeigten im Laufe einer Sitzung unbedeutende Schwankungen, wenn dem Auge Erholung gestattet wurde und die einzelnen Abzählungen von einander in beträchtlichen zeitlichen Zwischenräumen bewerkstelligt wurden. Die Schwankungen zwischen den an verschiedenen Tagen angestellten Messungen waren gleichfalls gering, wenn die Intensität des Spectrums anuähernd eine gleiche und der Himmel wolkenlos war. Von allen Farben wurden die grössten Schwankungen für Blau erhalten, da schon bei einer unbedeutenden Verminderung der Helligkeit des Spectrums die Empfindlichkeit gegen Blau beträchtlich abnahm. Ferner nahmen für jede Farbe die Schwankungen in dem Masse der Annäherung zur äussersten Peripherie der Netzhaut immer mehr und mehr zu und daher wurde hier noch mehr Aufmerksamkeit darauf verwandt, dass die Intensität des Spectrums bei den einzelnen Messungen eine möglichst gleiche war und dem Auge die gehörige Erholung gewährt wurde. Enalich bemerken wir noch, dass im Maasse der Uebung die Empfindlichkeit gegen Farben auf der Peripherie der Netzhaut gleichfalls merklich zunahm.

A. Innere Hälfte der Netzhant.

\begin{tabular}{|c|c|c|c|c|c|c|c|c|c|}
\hline $\begin{array}{l}\text { Ablen- } \\
\text { kung } \\
\text { des } \\
\text { Auges } \\
\text { i. Grad }\end{array}$ & \multicolumn{3}{|c|}{$\begin{array}{c}\text { Roti. } \\
\text { Empfindlichkeit } \\
\text { in Centrum }=1 / 19,7 \\
\text { Winkel } 2 \alpha=13^{\circ}\end{array}$} & \multicolumn{3}{|c|}{$\begin{array}{c}\text { Grün. } \\
\text { Empfundlichkeit } \\
\text { im Centrum }=1 / 5897 \\
\text { Winkel } 2 a=7^{0} 30^{\prime}\end{array}$} & \multicolumn{3}{|c|}{$\begin{array}{c}\text { Blau. } \\
\text { Empfindlichkeit } \\
\text { im Centrum }=1 / 268 \\
\text { Winkel } 2 \alpha=3^{\circ} 30^{\prime}\end{array}$} \\
\hline $\begin{array}{l}5^{0} \\
20 \\
25\end{array}$ & $\begin{array}{l}19^{0} 15^{\prime} \\
31^{\circ} \\
49^{\circ}\end{array}$ & $\begin{array}{c}1 / 9,2 \\
1 / 39 \\
10 / 17\end{array}$ & $\begin{array}{l}1: 2,1 \\
1: 5,2 \\
1: 11,25\end{array}$ & $\begin{array}{c}11^{\circ} \\
17^{\circ} 20^{\prime}\end{array}$ & $\begin{array}{l}1 / 27,5 \\
1 / 11,26\end{array}$ & $\left|\begin{array}{ll}1: & 2,1 \\
1: & 5,2\end{array}\right|$ & $\begin{array}{l}5^{\circ} 30^{4} \\
8^{0}\end{array}$ & $\begin{array}{l}1 / 109 \\
1 / 5196\end{array}$ & $\left\{\begin{array}{l}1: 2,46 \\
1: 5,2\end{array}\right.$ \\
\hline
\end{tabular}




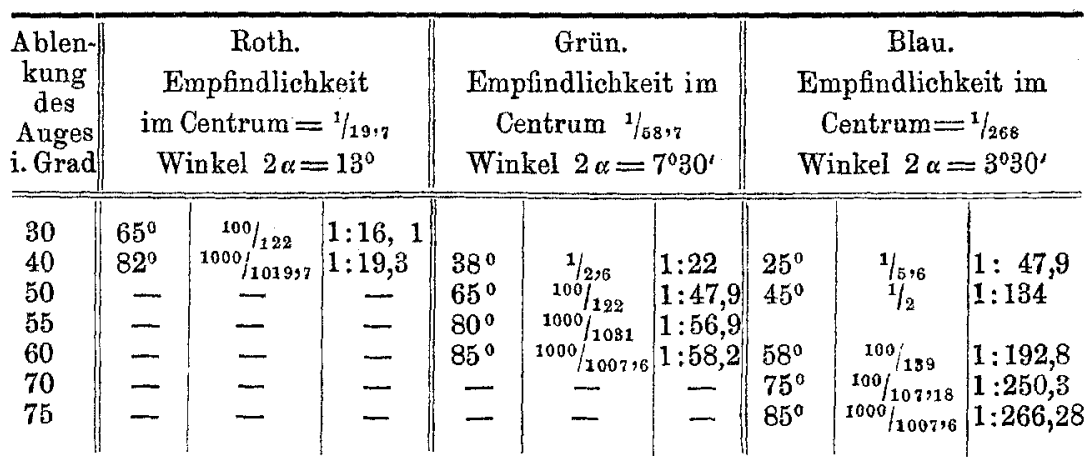

B. Aeussere Hälfte der Netzhaut

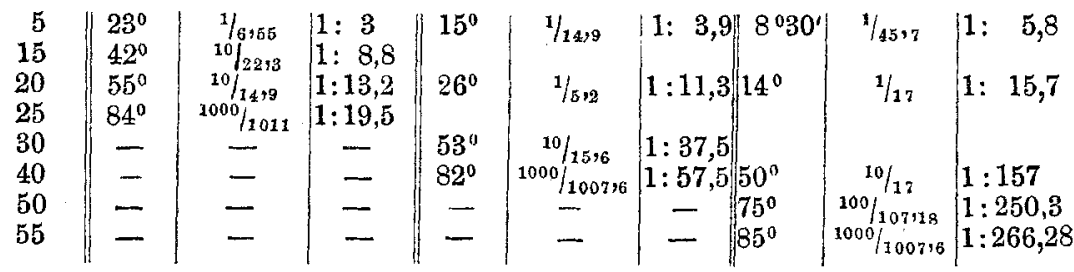

In den beiliegenden Tabellen werden die Grenzen der Perception der Farben auf der Peripherie der Netzhaut in der ersten Colonne durch die Anzahl von Graden angedeutet, für welche der nebenanstehende Winkel $2 \alpha$ grösser als $80^{\circ}$ ist, wo folglich der Unterschied in der Intensität der hellen und dunklen Streifen sehr gross sein muss, damit ihn das Auge wahrnehmen kann und wo daher der Bruch, der die Empfindlichkeit ausdrückt, nur um ein Geringes kleiner als 1 ist. Ueber die angegebenen Grenzen hinaus in der Richtung zur Peripherie unterscheidet das Auge im Spectrum keine dunkeln Streifen mehr.

Aber die angegebenen Grenzen stellen noch nicht die endgültigen Grenzen der Empfindlichkeit gegen verschiedene Farben dar. Letztere erstreckt sich auch noch weiter zur Peripherie bin, nur in unvergleichlich schwächerem Grade und daher ist sie schon einer Messung nach der oben beschriebenen Methode, die zur Bestimmung feinerer Unterschiede in der Intensität beider Felder bestimmt ist, nicht mehr zugänglich.

Um die äussersten Grenzen der Empfindlichkeit gegen Farben an der äussersten Peripherie der Netzhaut zu bestimmen, entfernte ich beide Nicols und die zwischen ihnen befindliche Gypsplatte, die vor dem Spectroskop standen und concentrirte dabei bisweilen bei Untersuchung der rothen und immer bei Untersuchung der blauen Farbe das Licht vermittelst einer Convexlinse, indem ich 
bemüht war, den zu untersuchenden Farben annähernd einen gleichen Grad von Helligkeit zu geben, zugleich aber es vermied, für die zu untersuchenden Farben das Maximum der Helligkeit zu nehmen, da beim Maximum der Helligkeit eine Farbenempfindung im Auge selbst in dem Falle erhalten wurde, wenn die aus dem Spectroskop ausgehenden Strahlen nur auf die Sclera allein fielen, wie dies weiter unten genauer erklärt werden wird. Dabei wurde der Kopf je nach Bedürfniss auf $40^{\circ}$ oder $60^{\circ}$ zur Seite gewandt und darauf das Auge noch auf dieselbe Seite auf eine solche Anzahl von Graden abgelenkt, bis jegliche Farben- und Lichtempfindung aufhörte. Hierbei wurde jedoch stets streng darauf geachtet, dass bei diesen Kopfbewegungen das Auge nicht aus dem Centrum des Halbkreises, in welchem sich dasselbe immer befinden muss, gerückt wurde und welches selbst wiederum in einer Linie mit der optischen Axe des Oculars liegen musste; sonst würden wir für die seitliche Ablenkung des Auges falsche Zahlen erhalten haben. Um die richtige Lage des Auges zn controliren, wandte ich jedesmal bei Ablenkung des Kopfes und Auges zur Seite, ohne die Lage des Kopfes zu verändern, das Auge wieder auf die entgegengesetzte Seite, d. h. nach der Seite des Oculars, zurück. Da das Farbenfeld bei mir Quadratform besass, so verlor dasselbe bei Verrückung des Auges aus dem Centrum des Halbkreises letztere Form, indem es die eines Rechtecks annahm. Noch vortheilhafter ist es bei solchen Untersuchungen dem Farbenfeld die Form eines Kreises zu geben, welche bei Verrückung des Auges zu einer ovalen wird.

Bei der Untersuchung der äussersten Greuzen des Gesichtsfeldes zeigen die für verschiedene Farben erhaltenen Zahlen gleichfalls Schwankungen, die einerseits von dem Zustande des zu untersuchenden Auges, von der grösseren oder geringeren Ermüdung desselben, - andererseits aber von der Intensität des Spectrums abhängen. Bei starker Helligkeit werden bekanntlich die Grenzen für sämmtliche Farben zur Peripherie hin gerückt. Wenn wir aber den zu prüfenden Farben annähernd einen gleichen Grad von Helligkeit geben, so erhalten wir hier stets dasselbe Resultat: d i e äusserst e Grenze für Roth liegt zum Centrum am nächsten, darauffolgt die GrenzefürGrün und am weitesten zur Peripherie hin liegt die Grenze für Blau. Hierzu müssen wir noch hinzufügen, dass sich ein bedeutenderer Zwischenraum zwischen der äussersten Grenze für Roth und Grün, 
als zwischen den Grenzen für Grün und Blau befindet. Was nun den Abstand zwischen der äussersten Grenze für Roth und der Grenze für Blau anbetrifft, so ist der Zwischenraum zwischen ihnen ein so bedeutender, dass diese Grenzen bei den einzelnen Untersuchungen einander nicht berühren, vorausgesetzt natürlich, dass der Unterschied in der Helligkeit bei den einzelnen Messungen nicht besonders gross und dabei die Helligkeit für Roth nicht grösser als die für Blau war.

Ich führe hier die Zahlen für die äussersten Grenzen an, die ich für das rechte Auge erhalten habe und die das Mittel aus 10 einzelnen Messungen zeigen:

$\begin{array}{cc}\text { an der inneren } & \text { an der äusseren } \\ \text { Hälfte der } & \text { Netzhaut. } \\ \text { für Roth } 80 & 65^{\circ} \\ \text { D Grün } 95 & 7^{\circ} \\ \text { Blau } 105 & 7^{\circ}\end{array}$

Dabei wird Blau ohne jede Veränderung des Farbentons bis zur äussersten Grenze percipirt, nur seine Intensität nimmt $a b$ und dasselbe erscheint dunkler. Was dagegen Roth und Grün betrifft, so geben diese in einem Abstande von $10-15^{\circ}$ von ihrer äussersten Grenze näher zum Centrum hin schon nahezu die Empfindung von Gelb und darauf an der äussersten Grenze selbst nur eine Lichtempfindung. Allerdings wird die Zone, auf welcher die angeführten Farben die veränderte Fmpfindung hervorrufen, desto schmäler, je intensiver das Spectrum ist, allein jene Zone ist stets vorhanden.

Wenn wir die Resultate unserer Untersuchungen resumiren finden wir Folgendes :

1) Auf der Peripherie der Netzhaut müssen wir zwei Zonen, unterscheiden, die allmählig in einander übergehen; die erste liegt näher zum Centrum und ist im Stande feinere Unterschiede in der Intensität der Farben wahrzunehmen; die $\mathrm{zweite}$ Zone liegt näher zur äussersten Peripherie, in ihr ist die Empfindlichkeit gegen Farben bedeutend schwächer und kann die Netzhaut nur durch die grösste Menge von farbigem Licht erregt werden. In dieser Beziehung herrscht somit eine vollkommene Analogie zwischen der Empfindlichkeit gegen Farben und der gewöhnlichen Sehschärfe, welche die Augenärzte vermittelst Buchstaben von verschiedener Grösse bestimmen und welche bekanntlich allmählig vom Centrum zur Peripherie abnimmt, so dass das Auge an der äussersten Pe- 
Ueber die Empfindlichkeit des Auges gegen die Lichtintensität etc. 459

ripherie nur gröbere Gegenstände wahrnehmen, so z. B. Finger zählen, Bewegungen der Hand unterscheiden kann.

Im äusseren Theil des Gesichtsfeldes, das dem Roth angehört, ist die erste Zone . . . . . . . . . . . . . . = $40^{\circ}$.

Die zweite Zone . . . . . . . . . . . . . . . $=40^{\circ}$.

Der ganze äussere Theil des Gesichtsfeldes. . . . . . . . $=80^{\circ}$.

Im inneren Theil des Gesichtsfeldes für Roth die erste Zone $=25^{\circ}$.

Die zweite Zone . . . . . . . . . . . . $=40^{\circ}$.

Die ganze innere Hälfte des Gesichtsfeldes . . . . . . . $=65^{\circ}$.

Die Grösse des ganzen Gesichtsfeldes für Roth somit $=145^{\circ}$.

Für Grün im äusseren Theile des Gesichtsfeldes die erste Zone $=55^{\circ}$.

Die zweite Zone .............. . . $=40^{\circ}$.

Der ganze äussere Theil des Gesichtsfeldes........ . $=95^{\circ}$.

Im innern Theil des Gesichtsfeldes die erste Zone. . . . . $=40^{\circ}$.

Die zweite ................. . . . $\mathbf{3 3}^{\circ}$.

Der ganze innere Theil des Gesichtsfeldes . . . . . . . = $73^{\circ}$.

Die Grösse des ganzen Gesichtsfeldes für Grün . . . . = $168^{\circ}$.

Für Blau im äusseren Theil des Gesichtsfeldes die erste Zone $=75^{\circ}$.

Die zweite Zone .............. . . . $=30^{\circ}$.

Der ganze äussere Theil des Gesichtsfeldes . . . . . = $=105^{\circ}$.

Im innern Theil des Gesichtsfeldes die erste Zone.... = $55^{\circ}$.

Die zweite................. . . . $=22^{\circ}$.

Die ganze innere Hälfte des Gesichtsfeldes . . . . . . . $=\mathbf{7 7}^{\mathbf{0}}$

Die Grösse des ganzen Gesichtsfeldes für Blau. . . . = 1820.

Somit ist das blaue Gesichtsfeld um $47^{\circ}$ grösser als das rothe und um $14^{0}$ grösser als das grüne, das grüne Gesichtsfeld um $23^{0}$ grösser als das rothe. Was das Verhältniss zwischen den Zonen betrifft, so ist die erste von ihnen für Roth am kleinsten und für Blau am grössten; das Umgekehrte sehen wir an der zweiten Zone, die für Roth grösser und für Blau kleiner ist.

Die äu sserst e Grenze für Roth liegt im äusseren Theil des Gesichtsfeldes (also an der innern Hälfte der Netzhaut) um $15^{\circ}$ weiter zur Peripherie im Vergleich mit dem inneren Theil des Gesichtsfeldes. Ein ähnliches Verhältniss zwischen beiden Hälften hatte $S \operatorname{chelske}^{1}$ ) schon früher gefunden. Für Grün liegt dieselbe Grenze im äusseren Theil des Gesichtsfeldes um $22^{\circ}$ und für Blau um $28^{\circ}$ weiter, als im inneren.

2) Die Empfindlichkeit gegen Farben beginnt s of ort im Maasseder Entfernung von der Stelle des di-

1) Archiv für Ophthalmol. Bd. IX, III, S:45.

E. Pflüger, Archiv f. Physiologie. Bd. XII. 
recten Sehens abzunehmen, so dass es genügt, die Sehlinie um $2^{0}$, ja sogar um $1^{0}$, zur Seite zu lenken, um schon eine merkliche Abnahme der Empfindlichkeit zu erhalten; auf dem Abstande von $5^{0}$ nach innen von der fovea centralis, a 1 s 0 in der Nähe der Grenze des gelben Flecks ${ }^{1}$ ) fällt sie für alle Farben ein wenig mehr als um das Zweifache im Vergleich mit der centralen Empfindlichkeit; in der Entfernung von $5^{0}$ nach aussen ist diese Abnahme noch bedeutender.

3) Ueberhaupt fällt die Empfindlichkeit gegen Farben ander äusseren Hälfte der Netzhaut bedeutend schneller als anderinnern Hälfte. Dieser Unterschied ist schon innerhalb der Grenzen des gelben Fleckes bemerkbar, so dass in einer Entfernung von $5^{0}$ nach aussen von der fovea centralis die Empfindlichkeit gegen alle Farben schon bedeutend geringer ist, als in der entsprechenden Entfernung an der innern Hälfte der Netzhaut, wie dessen schon oben erwähnt worden ist; so ist sie für Roth fast um $1 \frac{1}{2}$, für Grün fast um 2, und für Blau um $2 \frac{1}{2} \mathrm{mal}$ geringer. Auf der weiteren Ausdehnung der Netzhaut zur Peripherie hin nimmt dieser Unterschied in der Empfindlichkeit der beiden Hälften noch mehr zu. Diese Thatsache zeigt und erklärt uns zugleich, dass auch die äussersten Grenzen für Farben in der äusseren Hälfte der Netzhaut nothwendigerweise näher zum Centrum liegen müssen, als in der inneren.

4) Die Empfindlichkeit gegen Farben, die schon innerhalb der Grenzen des gelben Flecks fällt, fährt auf der weiteren Ausdehnung der Netzhaut immer mehr und mehr fort abzunehmen. Wenn wir die Abnahme der Empfindlichkeit an der Peripherie für jede Farbe einzeln verfolgen, so gelangen wir zu dem Schlusse, dass Anfangs, d. h. inder nächsten Umgebung des gelben Flecks diese Abnahme bedeutend schneller vor sich geht und darauf am Endeder ersten Zone etwas langsamer wird.

Um sich yon der Richtigkeit des gezogenen Schlusses zu überzeugen, muss man zusehen, in welchem Verhältnisse die Empfind-

1) Die Grösse des gelben Flecks ist im horizontalen Durchmesser durchschnittlich $=2-3 \mathrm{Mm}$. (Handbuch der gesammten Augenheilk. von Saemisch u. Graefe, Bd. I, I. S. 429) oder für das emmetropische Auge = $7,7^{0}-11,6^{\circ}$. 
Ueber die Empfindlichkeit des Auges gegen die tichtintensität etc. 461

lichkeit an verschiedenen peripherischen Stellen zu einander steht. Da auf den oben angeführten Tabellen A und B nur das Verhältniss der peripherischen Empfindlichkeit zur centralen angegeben ist, so lässt sich nach ihnen nicht so leicht über das Verhältniss zwischen der Empfindlichkeit an verschiedenen Stellen der Peripherie urtheilen. Wir führen daher kleine Tabellen für jede Farbe an:

\section{Roth.}

Innere Hälfte.

Im Centrum und auf $5^{\circ}$ von dems. $=1: 2,1$. auf $5^{\circ}$ und $20^{\circ}=1: 2,47$.

Im Centrum u. auf $20^{\circ}=1: 5,3$. auf $20^{\circ}$ u. $40^{\circ}=1: 3,7$.
Aeussere Hälfte der Netzhaut.

Im Centrum und auf $5^{\circ}=1: 3$. auf $5^{0}$ und auf $15^{\circ}=1: 3$. auf $15^{\circ}$ und auf $25^{\circ}=1: 2,2$.

Grün.

$$
\begin{array}{rlrl}
\text { Im Centrum und auf } 5^{\circ} & =1: 2,1 . & \text { Im Centrum und auf } 5^{\circ} & =1: 3,9 . \\
\text { auf } 5^{\circ} \text { und } 20^{\circ} & =1: 2,45 . & \text { anf } 5^{\circ} \text { und auf } 20^{\circ} & =1: 2,86 . \\
\text { Im Centrum und auf } 20^{\circ} & =1: 5,2 . & \text { Im Centrum u. auf } 20^{\circ} & =1: 11,3 . \\
\text { auf } 20^{\circ} & \text { u. } 40^{\circ}=1: 4,3 . & \text { auf } 20^{\circ} \text { und auf } 40^{\circ}=1: 5 . \\
\text { auf } 40^{\circ} \text { u. } 60^{\circ} & =1: 2,5 . &
\end{array}
$$

Blau.

$$
\begin{aligned}
\text { Im Centrum und auf } 5^{\circ} & =1: 2,46 . \\
\text { auf } 5^{\circ} \text { u. auf } 20^{\circ} & =1: 2,1 . \\
\text { Im Centrum und auf } 20^{\circ} & =1: 5,2 . \\
\text { auf } 20^{\circ} \text { u: auf } 40^{\circ} & =1: 9,2 . \\
\text { auf } 40^{\circ} \text { u. auf } 60^{\circ} & =1: 4 . \\
\text { auf } 60^{\circ} \text { u. auf } 75^{\circ} & =1: 1,4 .
\end{aligned}
$$

$$
\begin{aligned}
\text { Im Centrum und auf } 5^{\circ} & =1: 5,8 . \\
\text { auf } 5^{\circ} \text { und auf } 20^{\circ} & =1: 2,7 . \\
\text { Im Centrum und auf } 20^{\circ} & =1: 15,7 \\
\text { auf } 20^{\circ} \text { und auf } 40^{\circ} & =1: 10 . \\
\text { auf } 40^{\circ} \text { und auf } 55^{\circ} & =1: 1,7 .
\end{aligned}
$$

Wenn wir in den angeführten Tabellen die Empfindlichkeit an den näher zum Centrum gelegenen Stellen mit der Empindlichkeit der mehr peripherischen Stellen, z.B. das Verhältniss der Empfindlichkeit im Centrum und auf $20^{\circ}$ einerseits und das Verhältniss von $20^{\circ}$ und $40^{\circ}$ andererseits vergleichen, so finden wir, dass die Empfindlichkeit auf der Strecke von $20^{\circ}-40^{\circ}$ langsamer abnimmt, als auf der Strecke vom Centrum bis $20^{\circ}$. Eine einzige Ausnahme finden wir für Blau auf der inneren Hälfte der Netzhaut, wo die Empfindlichkeit von $20^{\circ}-40^{\circ}$ bedeutend mehr abnimmt, als auf der Strecke vom Centrum bis $20^{\circ}$, was vielleicht nur von den beträchtlichen Schwankungen abhängt, die man bei der Messung der Empfindlichkeit gegen BJau erhält. Bei der 
Vergleichung des Verhältnisses zwischen Centrum und $5^{0}$ einerseits und $5^{\circ}$ und $20^{\circ}$ andererseits darf man nicht ausser Acht lassen, dass der letztere Abstand dreimal grösser ist, als der erstere.

5) Wenn wir unsere Aufmerksamkeit darauf richten, ob die Abnahme der Empfindlichkeit gegen alle Farben gleichmässig erfolgt, so ergiebt es sich, dass in der nächsten Umgebung der fovea centralis auf $5^{0}$ nach innen, ein Unterschied in der Abnahme sehr schwach ausgedrückt ist, obgleich man auch hier schon sieht, dass die Empfindlichkeit gegen Blau schneller abnimmt, als gegen die anderen Farben; auf der äusseren Hälfte der Netzhaut tritt der Unterschied in derselben Entfernung vom Centrum schon unvergleichlich frappanter hervor, indem die Empfindlichkeit für Roth um 3, für Grün um 3,9 und für Blau um 5,8 mal fällt. Wenn auch Stellen vorkommen, wie z. B. auf $20^{\circ}$ nach innen von der fovea centralis (s. Tab. A), wo die Empfindlichkeit für alle Farben gleichmässig um 5,2 mal fällt, so wird man dies vielleicht eher einem zufälligen Zusammenfallen der Ziffern zuzuschreiben haben. Wie dem auch sei, wenn schon in der Nähe des Centrums und besonders nach innen hin die Abnahme ziemlich gleichmässig für alle Farben erfolgt, so hört diese Gleichmässigkeit weiter zur Peripherie hin auf, und zwar an der äusseren Hälfte der Netzhaut schneller, als an der inneren, in Folge dessen, dass die Empfindlichkeit gegen Blau im Vergleich mit den übrigen Farben schneller abnimmt.

Wenn es nun richtig ist, dass die Empfindlichkeit nicht für alle Farben gleichmässig abnimmt, so dürfen wir schon nicht erwarten, dass sich an der Peripherie zwischen der Empfindlichkeit gegen verschiedene Farben dasselbe Verhältniss erhält, welches im Centrum vorhanden ist, dass z. B. die Empfindlichkeit gegen Blau überall die gegen Roth um 13,6 mal übertrifft, wie wir dies im Centrum vorfinden. Um dieses Verhältniss zwischen der Empfindlichkeit gegen Farben an verschiedenen Stellen der Netzhaut zu verfolgen, führe ich dasselbe in 2 Tabellen vor, von denen No. 1 anzeigt, um wie viel mal die Empfindlichkeit gegen Blau die gegen Roth an verschiedenen Stellen der Netzhaut übertrifft, während No. 2 angiebt, um wie viel mảl sie grösser ist, als die Empfindlichkeit gegen Grün. 
Veber die Empfindlichkeit des Auges gegen die Lichtintensităt etc. 463

1.

$$
\begin{aligned}
\text { Im Centrum } & =13,6 . \\
\text { nach innen auf } 5^{0} & =11,85 . \\
, \quad, \quad, 20^{\circ} & =13.8 . \\
, \quad, 40^{\circ} & =5,47 . \\
\text { nach aussen anf } 5^{\circ} & =7 . \\
, \quad, \quad 20^{\circ} & =11,4 .
\end{aligned}
$$

2.

$$
\begin{aligned}
& \text { Im Centrum } \quad=4,5 \text {. } \\
& \text { nach innen auf } 5^{0}=4 \text {. } \\
& \text {., } \quad, \quad 20^{\circ}=4,6 \text {. } \\
& \text {, " }, 40^{\circ}=2,15 \text {. } \\
& \text {, " , } 50^{n}=1,6 \text {. } \\
& " \quad, \quad, 60^{\circ}=1,37 \text {. } \\
& \text { nach aussen auf } 5^{\circ}=3 \text {. } \\
& \text {,. } \quad, \quad, 20^{\circ}=3,2 \text {. } \\
& \text { " } \quad, \quad 40^{\circ}=1,7 \text {. }
\end{aligned}
$$

Allerdings kommen unter diesen Zahlen wie auch in allen oben angeführten Tabellen einzelne Zahlen vor, welche sowohl mit den vorhergehenden, als auch mit den nachfolgenden Zahlen wenig harmoniren, aber dies beweist nur die grosse Schwierigkeit solcher Untersuchungen, die Unvermeidlichkeit der dabei erhaltenen Schwankungen und die Nothwendigkeit fernerer Untersuchungen hinsichtlich dieser Frage. In Berücksichtigung jedoch aller Schwankungen und Fehler, welche bei solchen Messungen vorkommen, müssen wir doch den sehr wichtigen und unzweifelhaften Schluss ziehen, dass trotz dessen, dass die Empfindlichkeit gegen Blau an der Peripherie der Netzhaut im Vergleich mit den übrigen Farben schneller abnimmt und in Folge dessen das gegenseitign Verhältniss ihrer Empfindlichkeit sich ändert, dass trotz dessen, sage ich, auf der ganzen Peripherie die Fmpfindlichkeit gegen Blau die gegen Grïn bedeuteind und noch mehr die Empfindlichkeit gegen Roth übertrifft; die Empfindlichkeit gegen Grün ist zugeich überall grösser, als die gegen Roth.

6) Was die Frage über Farbenblindheit in der Nähe der äussersten Peripherie anbetrifft, so geht aus den oben angeführten Zahlen, die die äussersten Grenzen für die verschiedenen Farben bezeichnen, hervor, dass in der Nähe der äussern Peripherie vor allen die Fähigkeit zur Perception der rothen Farbe abgeschwächt und darauf völlig aufgehoben wird; hierauf geht die Fähigkeit, grüne Farbe zu empfinden, verloren, so dass an der äussersten Peripherie nur die Empfindung von blauer Farbe erhalten bleibt. Der Abstand zwischen den Grenzen für die einzelnen Farben ist zu gross, als dass in dieser Beziehung irgend ein Zweifel übrig bleiben könnte: die Grenze für Grün liegt durch- 
schnittlich an der inneren Hälfte der Netzhaut um $15^{\circ}$ und an der äusseren Hälfte um $8^{0}$ weiter, als die Grenze für Roth; die Grenze für Blau ist an der inneren Hälfte der Netzhaut um $10^{\circ}$ und an der äusseren um $4^{0}$ von der Grenze der grünen Farbe entfernt.

Ausserdem bestimmte ich die Grenzen des Gesichtsfeldes für weisse Farbe am Perimeter mit Hülfe eines Stearinlichtes und hierbei ergab es sich, dass die äussersten Grenzen für weisse und blaue Farbe untereinander vollkommen zusammenfallen. Das Gesichtsfeld für weisse Farbe ist $=180^{\circ}$, wovon $105^{\circ}$ auf den Antheil der äussern und $75^{\circ}$ auf den Antheil der innern Hälfte kommen. Für Blau liegt die Grenze im äusseren Theil des Gesichtsfeldes gleichfalls auf $105^{\circ}$ vom Centrum, im inneren Theil dagegen zeigte sie Schwankungen zwischen $75^{\circ}$ bis $80^{\circ}$ und lag durchschnittlich auf $77^{\circ}$. Somit liegt scheinbar die Grenze für Blau weiter $a b$, als die für Weiss. Dieser Unterschied wird jedoch genügend dadurch erklärt, dass am Perimeter die Bestimmung der Grenzen für den innern Theil des Gesichtsfeldes in Folge dessen Schwierigkeiten darbietet, dass dieser Theil des Gesichtsfeldes durch die Nase begrenzt wird; obgleich ich zur Umgehung ihres Einflusses das Auge vom Fixationspunkt stets auf $20-30^{\circ}$ seitlich ablenkte, wodurch diese Hälfte des Sehfeldes vergrössert wurde, so gelingt es doch nicht, dadurch die Einwirkung der Nase vollkommen zu beseitigen. Bei der Bestimmung der Grenzen für Farben mit Hülfe des Spectroskops dagegen hindern die anliegenden Theile in keiner Weise, da das Auge dabei gerade in der Richtung der optischen Axe des Oculars eingestellt wird.

Die von mir gefundenen Resultate werden durch die neueren Untersuchungen von $K 1 \cup g^{1}$ ) bestätigt, nach welchem am weitesten an der Peripherie Blau, darauf Grün und Gelb und am nächsten zum gelben Fleck Roth und Orange wahrgenommen wird. Wo i n ow ${ }^{2}$ ) findet ebenfalls, dass Gelb und Blau weiter als andere Farben an der Peripherie percipirt werden; an der äussersten Peripherie sind jedoch, seiner Ansicht nach, nur Licht percipirende Elemente vorhanden. $\mathrm{Zu}$ dieser letzteren Voraussetzung gelangt er daher, dass sowohl weisse, als auch farbige Flächen an der änssersten Peri-

1) Archiv für Ophthalmol. Bd. XXI, I. S. 285.

2) Ibidem, S. 234 . 
pherie nur Licht- und nicht Farbenempfindung bewirken, welche letztere unausbleiblich wäre, wenn daselbst Farben percipirende Elemente vorhanden wären. Natürlich können wir die Existenz von Lichtelementen an der äussersten Peripherie in keiner Weise in Abrede stellen; allein die Sache ist die, dass die angeführten Thatsachen uns kein Recht geben, daselbst nur die Existenz von Licht percipirenden Elementen zuzulassen und die von Farben percipirenden Elementen abzustreiten, da dieselben durch die verminderte Empfindlichkeit gegen Farben an der Peripherie der Netzhaut genügend dargethan werden. Schw a che Empfind ungen von farbigen 0 bjecten verlieren gewöhnlich ihren farbigen Charakter und ähern sich den Empfindugen von grauem oder weissem Licht. Dasselbe beobachten wir auch am Centrum der Netzhaut. Schon Helmholtz (Physiol. Optik, S. 300) wies darauf hin, dass ein farbiges Feld, wenn es eine geringe Grösse besitzt, grau oder weiss erscheint. Von der Richtigkeit dieser Erklärung kann man sich leicht mit Hülfe des Spectroskops überzeugen. Wenn man die Spalte im Collimator verdeckt und dieselbe nach und nach öffnet, erhält unser Auge, bevor es irgend welche Farben zu unterscheiden beginnt, vom schwachen Spectrum die Empfindung von weissem oder grauem Licht. Noch besser gelingt dieser Versuch, wenn wir die Intensität des Spectrums vermittelst zweier, vor das Spectroskop gestellten Nicols abschwächen und den einen von ihnen um die Axe des anderen drehen.

Es bleibt uns noch übrig, einige Bemerkungen über die Untersuchungen $\mathrm{L}$ an $\mathrm{d}_{0} \mathrm{lt}^{\mathrm{t}} \mathrm{s}^{1}$ ) $\mathrm{zu}$ machen, welche nicht nur mit den von mir oben mitgetheilten Resultaten, sondern auch mit den Untersuchungen von $\mathrm{Helmholtz}$ und $\mathrm{Schelske}$ über Blindheit gegen rothe Farbe auf der Peripherie der Netzhaut in directem Widerspruche stehen. Landolt behauptet in kurzen Worten, dass er alle Farben bis zur äussersten Peripherie (wenigstens bis $90^{\circ}$ nach aussen) richtig wahrnahm, wenn sie nur genügend jntensiv waren. Seine Untersuchungen stellte er theils mit farbigen Papierstückchen, die er in einem dunklen Zimmer durch directes Sonnenlicht erleuchtete, hauptsächlich aber mit hellen Spectralfarben an. Zunächst fällt uns auf, dass Landolt nicht ein Wort über die

1) Klin. Monatsblätter 1873, S. 376 . 
Methode seiner Untersuchungen mittheilt, wie er das Spectrum erhalten, ob vermittelst eines Spectroskops oder eines Prisma, indem er das Spectrum auf einem Schirme auffieng, wie dieses Schelske that; in gleicher Weise erwähnt er mit keinem Worte dessen, wie er die Farben isolirte, und was ihm als Garantie dafür diente, dass seine Sehlinie in der That um $90^{\circ}$ seitlich abgelenkt war. Ein solches Schweigen über die wesentlichsten Punkte und noch dazu in einer solchen Frage, bei deren Erörterung selbst solche competente Forscher, wie $\mathrm{Helmholtz}, \mathrm{Schelske} \mathrm{u}$. A. ihre Untersuchungsmethode häufig bis in's Detail beschreiben, wird wohl kaum das Zutrauen zu den Resultaten Landolt's vergrössern können, da es dem Leser jede Möglichkeit, über die Tauglichkeit der Methode und den Werth der erhaltenen Resultate urtheilen zu können, raubt.

Aber auch aus jener kurzen Mittheilung, die Landolt macht, ist ersichtlich, dass er einige wichtige Fehlgriffe begangen hat: a) Er nimmt ohne Grund an, dass die äusserste Grenze des äusseren Theils des Gesichtsfeldes auf $90^{\circ}$ liegt; bei mir befindet sie sich auf $105^{\circ}$, und ich kenne Personen, bei denen sie noch weiter, bisweilen sogar bis $115^{0}$, liegt. Wie es scheint, zweifelt $\mathrm{L}$ a $\mathrm{n}$ d olt selbst daran, dass die äusserste Grenze in der That unter $90^{\circ}$ liegt, da er den Ausdruck gebraucht: mindestens bis $90^{\circ}$; als ob es ihm bisweilen gelungen sei, Farben auch über $90^{\circ}$ hinaus wahrzunehmen, wie weit aber namentlich, dessen erwähnt er nicht. Es wäre daher besser gewesen, anfänglich die äusserste Grenze für Weiss zu bestimmen und darauf mit dieser, bei Vermeidung aller unbestimmten Ausdrücke, die Grenze für Farben zu vergleichen. b) Bei der Untersuchung der Frage über Farbenblindheit ist nicht allein das wichtig, dass bestimmte Farben noch eine Empfindung, z. B. auf $90^{\circ}$, hervorrufen, sondern es ist auch sehr wichtig, zu beachten, ob die peripherische Empfindung sich von der centralen hinsichtlich des Farbentons unterscheidet. Intensives Roth kann auch in einem für Roth blinden Abschnitte eine Empfindung hervorrufen, aber diese Empfindung wird schon einen anderen Charakter besitzen und diese Veränderung des Charakters der Empfindung bejaht die Frage über Existenz von Farbenblindheit an der Peripherie. Der Untersuchende kann jedoch, wie ich mich davon überzeugt habe, die Farbe, die er vor sich hat, dabei ricbtig erkennen und nennen, obgleich die Empfindung einen von dem centralen verschiedenen Cha- 
Ueber die Empfindlichkeit des Auges gegen die Lichtintensität etc. 467

rakter besitzt; denn in dem für Roth blinden Abschnitte ist doch die von dieser Farbe hervorgerufene Empfindung verschieden von denjenigen, die andere Farben bewirken, und zwar sind hinsichtlich der Veränderung der Farbenempfindungen an der Peripherie in den Hauptpunkten alle Beobachter, von denen einige auch mit spectralen Farben gearbeitet haben, einverstanden.

c) L a n d o $1 \mathrm{t}$ legt besonderes Gewicht darauf, dass er sich mit den hellsten Spectralfarben beschäftigt hat und dieses eben hat, wie sich vermuthen lässt, ihn mit allen andern Beobachtern in $\mathrm{Wi}$ derspruch gebracht. Bei Benutzung von sehr intensiven Spectralfarben kann es in der That den Anschein haben, als $o b$ alle Farben bis zur äussersten Perjpherie wahrgenommen werden können; für die äusserste Peripherie erhält man hierbei jedoch bisweilen so grosse Zahlen $\left(120^{\circ}\right.$ und sogar bedeutend mehr), die deutlich darauf hinweisen, dass an diesen Stellen nicht einmal eine einfache Lichtempfindung stattfinden kann.

Ein ganz einfacher Versuch kann uns vor einem grossen Irithum bewahren. Wenn wir ein sehr intensives Spectrum nehmen und die rothe Farbe in das Gesichtsfeld einstellen, so erhalten wir auf weissem Papier, das wir vor das Spectroskop halten, ein deutliches, helles und scharf contourirtes Bild von rother Farbe, dessen Grösse zunimmt und dessen Intensität abnimmt in dem Maasse, als wir den Schirm vom Spectroskop entfernen. Wenn ich nun mein Auge vor das Spectroskop in der Weise einstelle, dass das rothe Bild a u $f$ der Sklera in der Entfernung von einigen Millimetern von der Hornhaut erhalten wird, so empfängt das A uge dennoch eine deutliche Empfind ung von rother F a r be. Die Erklärung dieser Erscheinung liegt dárin, dass die Lichtstrahlen durch die Sklera in das Auge dringen und eine Farbenempfindung verursachen; der angeführte Versuch bietet somit einige Analogie mit dem Versuche von $\mathrm{M} u ̈ l l$ e $r$ dar, wo wir vermittelst einer Convexlinse das Licht auf der Sklera concentriren, um die Netzhautgefässe sichtbar zu machen; oder aber ein Theil des farbigen Lichts wird von der Sklera hierbei reflectirt und kann durch die Hornhaut in's Auge gelangen und Farbempfindung hervorrufen. Denselben Versuch stellte ich auch bei meinen Collegen an, und zwar mit gleichem Resultate. Wie wir den Versuch auch erklären mögen, er beweist jedenfalls, dass unter den beschriebenen Bedingungen die farbigen Lichtstrahlen auf einem ungewöhnlichen Wege 
in's Auge dringen. Aus diesem Grunde benutzte ich bei meinen ferneren Untersuchungen schon Farben von geringerer Intensität und sorgte hauptsächlich dafür, dass die zu prüfenden Farben einen annähernd gleichen Grad von Intensität besassen.

Noch mehr Fehler kann man in dem Falle begehen, wenn das Auge sich nicht in der Mitte des Halbkreises und gerade gegenüber der Axe des Oculars befindet, wie dies schon oben bemerkt wurde, und besonders dann, wenn der Beobachter dabei mit seinem Kopfe Bewegungen nach rechts und links ausführt, wie ich es bei Einigen bemerkt habe; unter diesen Umständen erhält man übergrosse und völlig falsche Zahlen für die Ablenkung des Auges in Graden. Endlich darf man nicht vergessen, dass man bei der Anwendung des Spectroskops, um im Gesichtsfelde verschiedene Farben zu erhalten, das Ocular zur Seite zu bewegen hat und dass somit für jede Farbe eine neue genaue Einstellung des ganzen Apparates nothwendig wird.

III.

\section{Ueber die Empfindlichkeit der Peripherie der Netzhant gegen Pigmentfarben.}

Die Untersuchung der Farbenfelder mit Hülfe von Pigmentpapierchen ausgeführt, giebt in den Hauptpunkten dieselben Resultate, wie ihre Untersuchung durch Spectralfarben.

Was die Grösse der Farbenfelder betrifft, so erhält man bei der Anwendung von Pigmentpapierstreifen verhältnissmässig einen geringen Unterschied im Vergleich mit der Grösse, die bei der Untersuchung mit Spectralfarben gefunden wurde. Ich führe hier die Zahlen an, die von mir am Perimeter bei Benutzung von pigmentirten Papierquadraten von $2 \mathrm{Cm}$. Grösse ermittelt wurden. Jedes farbige Quadrat wurde auf $\mathrm{sch}$ warzes Papier geklebt und allmählig zum Centrum, von der äussersten Peripherie ausgehend, gerückt; diejenige Stelle, wo von dem farbigen Quadrate eine Lichtempfindung erhalten wurde, galt als äusserste Grenze für die zu prüfende Farbe. Bei der Untersuchung der innern Hälfte des Gesichtsfeldes, also der äussern Hälfte der Netzhaut, wurde das Auge stets auf $20^{\circ}$ nach aussen vom Fixationspunkt abgelenkt, um den Einfluss der Nase auf die Grösse dieser Hälfte des Gesichtsfeldes zu verringern. Die von mir erhaltenen Zahlen waren folgende: 
Ueber die Empfindlichkeit des Auges gegen die Lichtintensität etc. 469

an der äussern an der innern

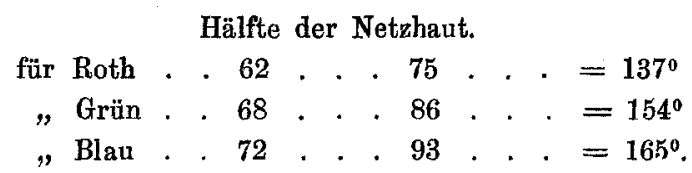

Wenn wir die Grösse dieser Felder mit derjenigen vergleichen, welche bei Benutzung der Spectralfarben ermittelt wurde, so finden wir, dass die erstere für Roth um $8^{0}$ für beide Hälften der Netzhaut, für Grün um $14^{\circ}$ und für Blau um $17^{\circ}$ kleiner ist, als die letztere. Hierbei müssen wir bemerken, dass auch hier d i e Gr ö ss e des Gesichtsfeldes für Blau fast vollkommen mit der für Weiss übereinstimmt, da das vermittelst Quadrate aus weissem Papier bestimmte Gesichtsfeld für die äussere Hälfte der Netzhaut $72^{\circ}$ und für die innere $95^{\circ}$ ergab; der ganze Unterschied beträgt also nur $2^{0}$ und stammt wahrscheinlich daher, weil das von mir angewanḋe blaue Papier nicht die genügende Intensität besass. Somit sind die von mir für die angeführten Farben ermittelten Grenzen bedeutend weiter, als die, welche von andern Beobachtern (Woin ow, Landolt, Briesewit z, Ra e hl mann, Holmgren, Bow u. A.) gefunden wurden. -

Ausser möglicher individueller Eigenthümlichkeiten sind auf die Grösse der Farbenfelder folgende Momente, die man daher auch bei ähnlichen Untersuchungen beobachten muss, von Einfluss: a) die Grösse der Farbenfelder. Im Hinblick auf die Controversen, welche in neuerer Zeit hinsichtlich dieses Gegenstandes entstanden sind ( $\mathrm{W}$ o in $\mathrm{ow}, \mathrm{Kr} \ddot{\mathrm{u}} \mathrm{kow}$ ), verwandte ich auf ihn besondere Aufmerksamkeit und es ward mir nicht schwer, mich von der Richtigkeit der Beobachtungen von $\mathrm{Helmholtz}$ und $\mathrm{A} u b e r t$ zu überzeugen, dass sich nämlich zugleich mit der Grösse des farbigen Objects auch das Gesichtsfeld vergrössert und seine äusserste Grenze zur Peripherie vorrückt. Ich wandte zu dem Zweck bei meinen Untersuchungen pigmentirte Papierquadrate von 1 und 2 $\mathrm{Cm}$. an und erhielt dabei fast immer einen Unterschied von $5^{0}$, bisweilen auch mehr, für jede Hälfte des Gesichtsfeldes. Dasselbe Resultat ergab sich auch bei Bestimmung des Gesichtsfeldes durch Spectralfarben: wenn ich an das Ocular des Fernrohres Behufs Isolirung der Farben ein Diaphragma mit kleinerer Oeffnung stellte, so verkleinerte sich hierbei stets die Breite der Farbenfelder auf $5^{\circ}$ oder mehr, je nach der Grösse der Oeffnung, durch welche das Licht passirte. 
b) Man erhält stets einen bedeutenden Unterschied, je nachdem, ob man die farbigen Objecte auf weissem oder schwarzem Grunde untersucht, so dass bei derselben Grösse der Objecte dieser Unterschied für mein Auge mitunter sogar bis $20^{\circ}$ für jede Hälfte des Sehfeldes stieg. Die grösste Breite der Farbenfeldererhält man in demFalle, wenndiefarbigen Objecteauf schwarzem Grunde untersuchtwerd e $\mathrm{n}$. Auf diesen Umstand wies zuerst $\mathrm{A} \mathfrak{a} \mathrm{b}$ e $\mathrm{r}$ hin, derselbe wurde aber in der Folge bezweifelt. - Dieser Umstand ist auch völlig begreiflich, da hierbei die Theile der Netzhaut, die in der Nachbarschaft der Stelle liegen, an welcher das Bild des farbigen Objects erhalten wird, sich im Zustande der Ruhe befinden und keinerlei Einfluss auf die Farbenempfindung selbst ausüben. Daher ist die letztere einerseits deutlicher und scharfer, andererseits dauernder. c) Die schnelle Ermüd ung der Peripherie der Netzhaut, auf die zuerst ebenfalls $\mathrm{A} u$ b e $\mathrm{rt}^{1}$ ) hingewiesen hat, muss man gleichfalls bei Bestimmung der Farbengrenzen durch Pigmentfarben beachten. An der weiteren Peripherie tritt die Farbenempfindung gewöhnlich nur im ersten Moment auf, wird darauf in Folge von Auftreten eines Nachbildes durch eine Lichtempfindung ersetzt und verschwindet endlich ganz. Daher muss man auch die Untersuchung häufig unterbrechen, um den Augen Erholung zu geben.

2) Bei der Untersuchung der Peripherie durch Pigmentfarben finden wir gleichfalls zwei Zonen; in der ersten, näher zum Centrum gelegenen sind die Farbenempfindungen gar nicht, oder nur wenig verändert, während in der zweiten, mehr peripherischen die Farbenempfindungen sich verändern und im Vergleiche mit denen im Centrum einen anderen Charakter annehmen.

Was die Grenze zwischen diesen beiden Zonen anlangt, so ändert sie sich, wie dies zuerst A u be r t dargethan hat: a) nach der Grösse des farbigen Objects; je grösser dieser letztere, desto breiter die erste Zone, und b) nach dem Grunde, auf welchem sich das farbige Object befindet: auf schwarzem Grunde ist die Breite der ersten Zone bedeutend grösser, als auf weissem. Aber auch bei gleichem Grunde und bei gleicher Grösse der Objecte ändert sich die Grenze zwischen beiden Zonen bei wiederholten Untersuchungen bedeutend, was zum Theil von verschiedenartiger Beleuchtung, zum

1) Archiv für Ophthalmol, Bd. III, II. S. 56 . 
Ueber die Empfindlichkeit des Auges gegen die Lichtntensität etc. 471

Theil aber auch vom Zustande des Auges selbst, von der grösseren oder geringeren Ermüdung desselben, abhängt; häufig wechselt die Grenze zwischen diesen Zonen sogar im Verlaufe derselben Sitzung, wenn diese lange Zeit währt und wird zugleich die Breite beider Zonen geringer.

Schematisch dürfen wir wohl annehmen, dass diese zwei Zonen den beiden Zonen entsprechen, die bei der Untersuchung mit Spectralfarben gefunden wurden. Ich musste aber darauf verzichten, zwischen ihnen genau die Grenze zu bestimmen und zwar in Folge der Unbeständigkeit derselben und der grossen Schwankungen in den Zahlen, die man bei der Untersuchung dieser Grenze erhält. In dieser Hinsicht theile ich vollkommen die Ansicht von $\mathrm{K} \mathrm{r} \mathrm{j} \mathrm{u} \mathrm{-}$ $\mathrm{k} 0 \mathrm{w}^{1}$ ), der eine Grenze, die die normale Farbenempfindung von der veränderten trennen soll, für willkürlich hält.

Somit bestätigen die von mir bei der Untersuchung der Peripherie durch Pigmentfarben erhaltenen Resultate in den Hauptpunkten die Resultate A uberts ${ }^{2}$ ).

Was nun den Unterschied betrifft, welchen man bei der Untersuchung der Peripherie mit Pigment- und Spectralfarben erhält, so wird derselbe einfach durch die geringere Intensität und Reinheit der Pigmentfarben erklärt, sowie durch die Unmöglichkeit, ihre Intensität willkürlich im erwünschten Grade zu verändern.

\section{Fxperimentelle Beiträge zur Physiologie der Bogengänge des Ohrlabyrinths.}

$$
\text { Von }
$$

\section{Dr. A. Bornhardt.}

(Aus dem physiologischen Laboratorium von Ad. Prof. Ustimovitch in St. Petersburg.)

Die umfangreiche Literatur unseres Gegenstandes sollte den neuen Forscher auf diesem Gebiete von vornherein abschrecken. Es schien mir jedoch, dass manche Lücke in der noch im Dunkeln

1) Archiv für Ophthalmol. Bd. XX. I. S. 275.

2) Archiv für Ophthalmol. Bd. III, II. S. 38-67. 